\title{
EL CONTRAPUNTEO ENTRE IMAGINARIOS SOCIALES Y EL DESARROLLO TURÍSTICO: EL CASO DE COSTA RICA
}

\section{The Counterpoint between Social Imaginaries and Tourism Development: the Case of Costa Rica}

\section{Esteban Barboza Núñez}

Profesor catedrático en la Universidad Nacional de Costa Rica, Costa Rica.

Correo-e: esteban.barboza.nunez@una.cr, ORCID: 0000-0002-2497-236

\section{Recibido: $22 / 6 / 2020 \bullet$ Aprobado: $27 / 7 / 2020$}

Cómo citar: Barboza Núñez, E. (2020). El contrapunteo entre imaginarios sociales y el desarrollo turístico: el caso de Costa Rica. Ciencia y Sociedad, 45(3), 45-63. Doi: https://doi.org/10.22206/cys.2020.v45i3.pp45-63

\section{Resumen}

Este artículo reflexiona acerca de la relación entre los imaginarios sociales y los modos en que el turismo ha sido incentivado y desarrollado en el caso particular de Costa Rica. Se esboza una crítica al modo en que los modelos de desarrollo turístico en Centroamérica y el Caribe tradicionalmente han sido analizados, a la vez que se propone el concepto teórico de imaginarios sociales como una posibilidad de análisis del desarrollo turístico en la región. Seguidamente, explica las relaciones entre imaginarios sociales mayores y los modos en que Costa Rica se ha desarrollado como referente turístico en la región, y cómo esos imaginarios se reflejan en el espacio turístico, el paisaje, la iconografía y los discursos contemporáneos acerca del turismo en el país.

Palabras clave: imaginación; turismo; desarrollo; Costa Rica.

\begin{abstract}
This article reflects on the relationship between social imaginaries and the ways in which tourism has been encouraged and developed in the particular case of Costa Rica. A critique of the way in which tourism development models in Central America and the Caribbean have traditionally been analyzed is outlined, while the theoretical concept of social imaginaries is introduced as a possibility of analysis of tourism development in the region. Next, it explains the relationships between major social imaginaries and the ways in which Costa Rica has developed as a tourist reference in the region, and how these imaginaries are reflected in the tourist space, the landscape and the iconography and contemporary discourses about tourism in the country.
\end{abstract}

Keywords: Imagination; tourism; development; Costa Rica. 


\section{Introducción}

Durante las últimas tres décadas, en los estudios turísticos en el contexto latinoamericano, especialmente en ámbitos como Centroamérica y el Caribe, e incluso en otros países de la región, en particular aquellos propicios para el desarrollo turístico de sol y playa, el análisis crítico del fenómeno ha favorecido, principalmente, el estudio de políticas públicas de inversión y desarrollo y sus efectos a nivel económico, social y ambiental. Desde la última década del siglo xx y las primeras del presente, los estudios en torno a las causas, características, e implicaciones del turismo en la región han versado sobre análisis macroeconómicos, descripciones de procesos de formulación e implementación de estrategias de desarrollo, y, al mismo tiempo, en estudios sobre sus implicaciones desde perspectivas críticas, sobre todo en cuanto a aspectos socio ambientales y económicos.

Siguiendo un enfoque sistémico del turismo, este trabajo plantea que, más allá de las políticas públicas o de las tendencias macroeconómicas globales, son los imaginarios sociales y, específicamente, los imaginarios turísticos, los que han servido de motores y justificadores ideológicos de los modelos implantados en la región, en pleno contrapunteo con las políticas públicas y disposiciones económicas regionales, A a pesar de esto, el análisis de los imaginarios es bastante menor en comparación con los estudios estructurales de los modelos y sus impactos económicos y socio ambientales. ${ }^{1}$ Se argumentará, que

1 A partir de la adopción en este artículo de un enfoque sistémico del turismo, - es decir, el turismo como un sistema compuesto por elementos de la más diversa índole, algunos insospechados, que interactúan y son interdependientes entre sí- se sigue el uso del concepto de modelos turísticos como representaciones de una realidad turística específica, de un destino en particular. En el caso de estudio en cuestión, se hará énfasis en el modelo de desarrollo turístico, en este caso de Costa Rica, que expresa la evolución del turismo en un determinado contexto, y en el modelo de impacto, que involucra el estudio de los impactos socioculturales, económicos y ambientales del turismo. los imaginarios sociales y turísticos son los que realmente intervienen como formadores de derroteros en cuanto a las estrategias de desarrollo turístico que serán implementadas en una región específica y sus posteriores consecuencias. Un país como Costa Rica, en el cual se centra este estudio, tanto por su imagen de paraíso tropical como por ser un destino de sol y playa caribeño por excelencia, con todos los matices que estas categorías implican, servirá de muestra de los modos en que los imaginarios sociales se entremezclan con la implementación y los resultados de los modelos de desarrollo propuestos, en una relación mucho más efectiva de lo que en primera instancia podríamos suponer.

El estudio del turismo en contextos como el costarricense, o bien en países aledaños de la región centroamericana y caribeña, incluyendo el Caribe mexicano, ha tendido enormemente a la recurrencia del estudio de caso. Trabajos como los de Allen Cordero (2006), o Luis Fernando Sandoval y Carlos Morera (2008), en un entorno como el costarricense, son claros ejemplos del uso de aportes de la economía política, principalmente a través del concepto de cadenas globales productivas, para argumentar que las grandes transnacionales hoteleras han marcado la pauta, en conjunción con políticas estatales de atracción de inversiones foráneas a la hora de centralizar la economía global, a través de una actividad como el turismo, en vez de difuminarla, como supuestamente debería ocurrir por medio de la inversión extranjera directa. Este tipo de análisis, acompañado por la enumeración y verificación de las consecuencias de esas estrategias de desarrollo, tanto a nivel social como ambiental, ha sido referentes en los estudios turísticos críticos en Costa Rica, desde inicios del siglo xxi hasta casi el presente. Trabajos posteriores, como los de Aurora Hernández y Juan Carlos Picón (2012), Ronald Arias y Jorge Coronado (2010), Diego Lobo Montoya (2016), Sofia Van Eghen (2011), Santiago Navarro (2013), Grettel Navas y Nicolás Cuvi (2015), o bien Edgar Blanco (2019), entre 
otros, han seguido esta tendencia.

En contextos aledaños, ya desde la década de los años noventa del siglo pasado, Sergio Molina y Sergio Rodríguez (1991), por ejemplo, señalaban la relación entre el turismo en algunos países de la región y la dependencia económica de periferias globales de sus metrópolis, en un claro uso de conceptos derivados de las teorías de la dependencia, la hegemonía y la interdependencia de los años sesenta y setenta del siglo pasado. En el presente siglo, son claves los trabajos y colectivos de Francisco Muñoz (2007), Antonio Aledo (2008), Ernest Cañada y Maciá Blásquez (2011), y Ernest Cañada (2010), entre otros, en los que aparecen estudios de casos de diferentes autores de Centroamérica, México y el Caribe, que enfatizan la exclusión de comunidades locales a partir del desarrollo inmobiliario, los efectos de la especulación inmobiliaria y las consecuencias socio ambientales, por citar, como resultado de las políticas enfocadas al desarrollo turístico y la atracción de inversión extranjera directa en el campo del turismo. Al mismo tiempo, se señala, en casi todos estos trabajos, cómo estos modelos de desarrollo no han significado una mejora en el bienestar social de las comunidades anfitrionas, o bien una reducción sustancial en la pobreza.

Este tipo de enfoques, especialmente el uso de recursos teóricos derivados de la economía política y las ciencias ambientales, en otros contextos ajenos a la región centroamericana y caribeña, ya se venía utilizando anterior a su aparición en la academia latinoamericana. Desde los años setenta y ochenta del siglo pasado, trabajos como los de Stephen Britton (1982) hablaban de conceptos como el turismo periférico o la teoría de la dependencia para argumentar que el colonialismo y el capitalismo perpetuaron, a través del turismo, una especie de relación de subordinación, aún en contextos postcoloniales, en los que los nuevos emporios hoteleros que abría el mercado turístico global en lugares como el Caribe, el sureste asiático o África, no hacían más que perpetuar la dependencia de las antiguas colonias en relación con sus metrópolis coloniales.

Estas ideas y sus aplicaciones estaban basadas en los postulados de teóricos como Samir Amin (1974), o Andre Gunder Frank (1978), cercanamente relacionados a la teoría de la dependencia. Otros autores, como Dennison Nash (1989), llegaron a pensar el turismo, en particular el de sol y playa meridional, como una forma de imperialismo, especialmente, al igual que lo consideró Britton, desde el punto de vista económico. Para Nash, los niveles de productividad de los países desarrollados permitían el ocio y el viaje de sus habitantes, por lo que, desde las metrópolis, se controlaba el turismo y su impacto en otras culturas, así como los tipos de desarrollo turístico en regiones periféricas.

Sin embargo, el uso de la teoría de la dependencia o la idea de la acumulación por desposesión, y los estudios de caso desde la óptica macroeconómica, o bien únicamente desde la crítica socio ambiental, del efecto del turismo en lugares receptores, tanto en América Latina como en otros contextos, no ha escapado de cuestionamientos que consideran que a través de estos enfoques se ha tendido a ver de manera monolítica las relaciones entre centros y periferias y el desarrollo turístico en nuestra región. Esta supuesta visión homogénea del turismo, o bien, este tipo investigaciones, no en pocas ocasiones promueven la noción de que en los países periféricos solo una forma de turismo es la dominante, la de gran escala, promovida por la inversión extranjera directa (Chaperon y Bramwell, 2013). Esto puede llegar a omitir u olvidar que existen otras formas de turismo a pequeńa escala, o bien el turismo interno; pero, más importante aún, puede causar que se prescinda de otros modos de análisis que vayan más allá del seguimiento de tendencias macroeconómicas globales aplicadas en espacios particulares, y de la descripción de sus consecuencias. 
Además, como apuntan Godfrey Baldacchino (2005) y Liam Campling (2006), el uso simplista de la teoría de la dependencia, o el abuso de los estudios de caso de realidades muy particulares, también puede convertir la investigación turística en determinista, y se puede llegar a ver las relaciones entre centros y periferias simplemente como marcadas por la explotación y el subdesarrollo. A menudo, el uso de estas teorías y metodologías también puede llegar a omitir aspectos positivos del turismo, o a no ver las diferencias o matices que existen dentro de los mismos países periféricos. Un caso como el de Costa Rica, por ejemplo, presenta particularidades difíciles de encontrar en sus vecinos, a pesar de que en estos también se haya tratado de implementar políticas de desarrollo turístico bastante similares, o bien, cuenten con atractivos turísticos que podrían competir en igualdad de condiciones.

Es por eso que es necesario plantearse un análisis desde una perspectiva sistémica, que no solamente describa a nivel sincrónico las repercusiones de ciertas estrategias de desarrollo turístico en lugares receptores, su encadenamiento con contextos macroeconómicos mayores, o bien la visión de que el turismo únicamente fomenta la dependencia económica de los países receptores en contextos como Centroamérica y el Caribe. También es necesario trazar el papel de los imaginarios en el devenir de un destino turístico, en los modos en que funciona, y en sus implicaciones, tanto positivas como negativas, según la óptica con que se mire.

\section{Imaginarios sociales, topofilia y geografías de la imaginación: su relación con el turismo}

Está bien documentado, en la costa del Pacífico norte de Costa Rica, en la provincia de Guanacaste, uno de los principales destinos turísticos de sol y playa del país, el caso de la controversial construcción de un hotel de la cadena RIU en 2008, en el que hubo comprobados daños ambientales y explotación laboral, tanto en el entorno del lugar donde se levantó el inmueble como con los trabajadores que lo construyeron, la mayoría migrantes nicaragüenses, y que incluyó la muerte de uno de ellos. Una de las acciones controversiales del proyecto fue la transformación radical del espacio que ocuparía el hotel y sus alrededores, y la afectación a los manglares, arroyos y arrecifes que formaban parte del ambiente antes de la existencia del hotel. Se denunció la tala de manglares y otros árboles, para tener una mejor vista al mar desde el hotel y eliminar elementos indeseables en el paisaje del lugar, la destrucción con dinamita de arrecifes y rocas en el mar para crear más espacio para que los bañistas pudieran nadar, y la construcción de rellenos ilegales, entre otras acciones perjudiciales para el ambiente (Navarro, 2013).

Ante estas acciones, podríamos recurrir al ensayo y análisis de varias posibles explicaciones. Evidentemente hubo violaciones a las normativas ambientales locales, que pudieron suceder por diversos motivos, entre ellos, la permisividad de las autoridades. Podríamos también atribuirle responsabilidades a la desmedida ambición de las multinacionales hoteleras y a su sistemático menosprecio por la cuestión medioambiental, de sobra comprobada por investigadores como el mismo Navarro (2013), quien documentó lo sucedido durante la construcción del hotel RIU en Guanacaste. También a las consecuencias del turismo de masas en destinos de sol y playa y a su insostenibilidad a largo plazo; o bien, el problema como resultado de políticas, en muchos casos implementadas de forma atropellada, de atracción de inversión extranjera directa.

Por otra parte, también es posible hurgar en otro lugar: el de los imaginarios. ¿No dictan estos, en el caso de un destino de sol y playa, que un lugar atractivo debe contar con arena blanca y mar azul, y no playas rocosas y manglares plagados de mosquitos, que no solo impedirían ciertas actividades lúdicas en 
el mar, sino que causarían una dislocación entre lo que los turistas imaginaron sería una playa tropical y lo que realmente encuentran? ¿No causaría esa dislocación o desentono un desempeńo del destino turístico en cuestión menor al de destinos rivales? Es decir, en este caso, lo que dictan los imaginarios turísticos de un destino como el descrito también es un factor a tomar en cuenta como causal, en este caso, de un desastre ambiental.

Es por eso que es importante recurrir a la cuestión de los imaginarios para poder entender mejor lo que sucedió en ese lugar, y lo que sucede en muchos destinos turísticos, desde que se plantean políticas de desarrollo y atracción de inversión extranjera directa, hasta que el destino esté en pleno funcionamiento, y aún después. Una de las premisas básicas de los teóricos de la cuestión de lo imaginario y su relación con la constitución de las sociedades modernas es no solamente abordar el asunto de la imaginación por sí misma, sino tratar de analizarla y entenderla como síntesis, y, principalmente, como fuente de lo real y de lo social; es decir, como modo de imaginarnos como personas, sociedades, naciones, y cómo nos desenvolvemos a partir de las formas en que nos imaginamos. Acá no se trata, entonces, de discutir si los imaginarios sociales son verdaderos o falsos, a partir de una "realidad" específica, más bien se trata de analizar los modos en que las sociedades se perciben, $y$, a la vez, se constituyen, se desarrollan y sobreviven.

Para tener una mejor comprensión de esta idea es fundamental la contribución de Cornelius Castoriadis (1975), quien sostiene que ningún orden social es pura funcionalidad. Más bien, afirma, las sociedades se organizan a través de significaciones imaginarias instituidas de manera simbólica. Es decir, todo lo que consideramos como dado o real en el entramado social está relacionado, y, de cierta forma, imbricado con lo simbólico, más allá de las posibles elecciones individuales que un sujeto crea que puede hacer. En toda sociedad existe una estructura compleja de instituciones y fuerzas instituyentes que viven en permanente tensión con símbolos ya instituidos, y en donde siempre existe la posibilidad de crear nuevos símbolos, aún no existentes.

Las sociedades, entonces, se revelan en sus instituciones; pero, al mismo tiempo, siempre tienen cierta apertura e indeterminación por aquello que aún no ha sido instituido. Presentan un carácter de auto constitución anónimo, y cada una se organiza a partir de esas significaciones que, a la vez, adiestran a los sujetos para que colaboren en su mantenimiento y en su reproducción. Como consecuencia de este funcionamiento y reproducción de las sociedades a partir de símbolos, las mismas se convierten en realidades históricas con alteraciones constantes de sus significaciones. Para Castoriadis (1975), el desarrollo del mundo a nivel histórico es fundamentalmente el desarrollo de las significaciones, y la cuestión histórica es la producción de nuevos sistemas de significados y significantes.

En cuanto a la constitución de las sociedades modernas - un tema muy importante en el ámbito del turismo, ya que este surge en plena modernidad-, las mismas están repletas de significaciones menores, no tan relevantes, que cambian constantemente para que las significaciones mayores y centrales no cambien nunca, incluso cuando ya hayan perdido el sentido con el que emergieron (Castoriadis, 1998). Es decir, existe en las sociedades modernas una suerte de repetición de lo mismo. Esta constante negación de la creación conduce a un ocultamiento de lo imaginario, y hace que la historia y las sociedades mismas se perciban como gobernadas por una instancia superior a ellas, y que lo imaginario se vea como falso, o como lo opuesto a la "realidad".

En resumidas cuentas, una sociedad no es solamente un sistema funcional para la convivencia 
de sujetos y para la satisfacción de sus necesidades. Pero tampoco es solamente una red de símbolos y de factores imaginarios. Las sociedades básicamente funcionan a partir de relaciones entre lo simbólico y lo imaginario, y su simbiosis con las prácticas cotidianas. Esta relación es la que les permite constituirse, existir y sobrevivir. Según Castoriadis, (1998) "la institución es una red simbólica, socialmente sancionada, en la que se combinan, en proporción y relaciones variables, un componente funcional y un componente imaginario" (p. 227).

Lo imaginario es lo que le da a la funcionalidad de cada sistema institucional su orientación específica; y no es lo que, en la vida cotidiana, o incluso en algunas corrientes de pensamiento marxista se cree: una forma de ocultamiento de lo real, o bien, una forma de dominación. Es más bien una condición de la existencia de lo real. Ese es tal vez uno de los mayores aportes de Castoriadis; el tratar de demostrar que lo imaginario no es falsa conciencia, ni ideología, ni mecanismo de dominación, y mucho menos lo que el término implica en el habla cotidiana, es decir, un invento o una ocurrencia alejada de lo real. Más bien, lo imaginario es un centro de creación y renovación de las significaciones que mueven y sostienen a las sociedades.

Además, los imaginarios sociales son, según otro importante teórico del tema, Charles Taylor (2006), mucho más que construcciones intelectuales elaboradas por filósofos o científicos sociales. Se trata más bien los modos en que la gente imagina su existencia social, las relaciones entre las personas, las expectativas, imágenes, ideas normativas, entre otros aspectos. Es decir, los imaginarios sociales no son el coto privado de una casta intelectual. Son más bien concepciones colectivas que todo mundo entiende, y que se manifiestan a través de imágenes, historias, leyendas, y que posibilitan prácticas comunes y un sentimiento ampliamente compartido de legitimidad.
Ahora bien, para aproximar el tema de los imaginarios al ámbito específico de los lugares, por ejemplo los destinos turísticos, y no necesariamente quedarse en el plano macro de sociedades más amplias o períodos históricos más abarcadores, una contribución valiosa en esta discusión es la noción de las geografías de la imaginación ${ }^{2}$, aportada por Edward Said (1978), y en parte basada en la idea de la topofilia y la poética del espacio, de Gaston Bachelard (1975). Said sostiene que existe un modo de pensar la geografía y los lugares a partir del uso de las nociones de mundo modernas más relevantes. Este modo de pensar y percibir imbrica imaginación con realidad, al punto de establecer un contrapunteo entre ambas, con claras implicaciones en la funcionalidad de los lugares según estos son imaginados. Para Said no existe un orden previamente establecido, y tampoco un ordenamiento histórico o social que funcione a partir, meramente, de designios económicos, como podrían argumentar algunos marxistas ortodoxos. Más bien, los modos en que muchos lugares cobran vida y funcionan se basan en atributos, a menudo metafóricos o emotivos, que, a través del lenguaje, les otorgamos, más allá de sus características geométricas u objetivas. A la vez, estos atributos implican formas de sustentar imágenes de lo propio y de lo local, de lo extraño y lo lejano.

2 En el texto original de Said, en inglés, este término aparece como imaginative geographies, el cual, traducido literalmente sería "geografías imaginativas". En la traducción al español del texto, el término aparece como "geografías imaginarias", —véase la traducción de María Luisa Fuentes, (2008). Barcelona: Debolsillo—, y en portugués — en la traducción de Tomás Rosa Bueno, (1990). Sao Paulo: Companhia das Letras-, por ejemplo, aparece como "geografias imaginativas". En el caso de este trabajo, se ha recurrido a traducirlo como "geografías de la imaginación", dado que la traducción estándar al español más bien parece querer dar a entender que el término implica algo meramente ficticio, con poca o ninguna conexión con las realidades de las geografías imaginadas y retratadas, ya sea de manera visual o escrita. El término escogido — geografías de la imaginación— se acerca más a la idea que trata de explorar Said. 


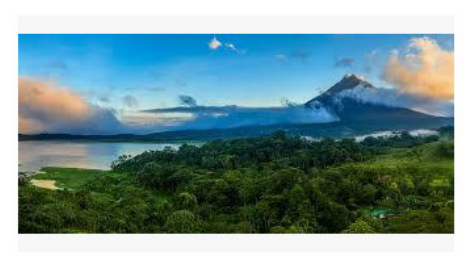

Vuelos a Costa Rica con Copa Airlines destinationsguide.copaair.com

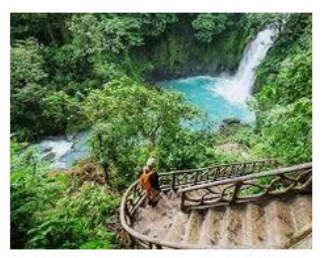

Costa Rica Travel Guide - Costa Rica T... backroads.com

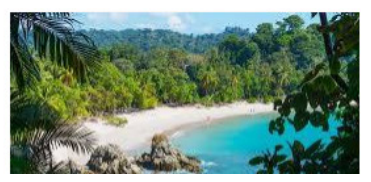

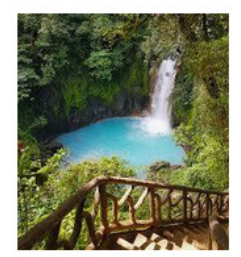

Cascadas increibles en la.. hola.com

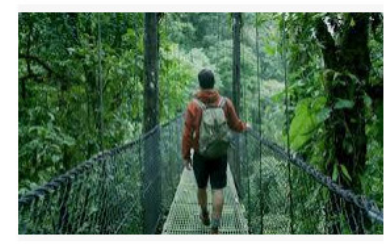

Visite Costa Rica I Sitio web oficial del turismo. Visite Costa Rica
visitcostarica.com

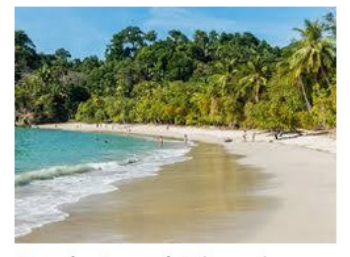

Por qué cada vez más latinoamericanos . infobae.com

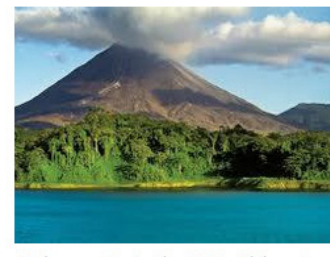

Turismo en Costa Rica 2020 - Viajes a C. dvisor.com.mx
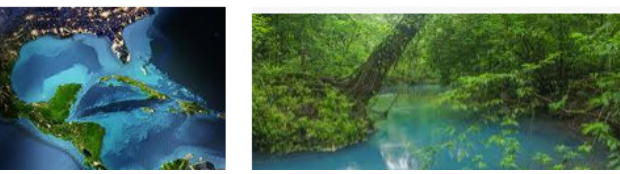

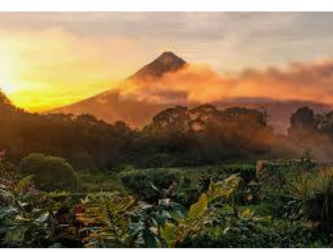

11 tips for travelling in Costa Rica - Rough ... roughguides.com

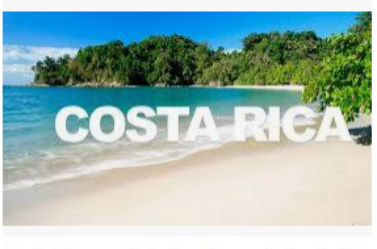

Costa Rica ocupó el primer lugar entre los desti.. larepublica.net

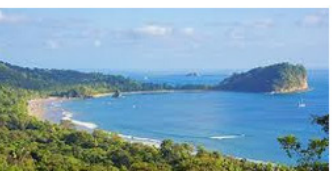

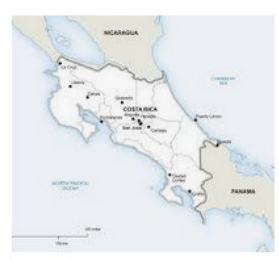

Diciembre 2019. Dengue en Cost. fundacionio.com

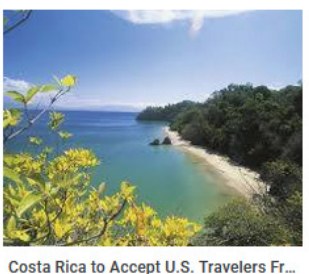
travelandleisure.com

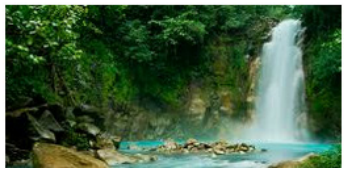

Figura 1. Resultado de búsqueda de "Costa Rica” en Google, en la que se muestra el predominio de elementos relacionados con la naturaleza

Fuente: https://www.google.com/search?q=costa + rica $\&$ tbm=isch\&ved=2ahUKEwj0j

Tanto las geografías de la imaginación como la historia contribuyen a que la mente intensifique su propio sentido de sí misma, al dramatizar la distancia y la diferencia entre lo cercano y lo lejano (Said, 1978). Estas geografías de la imaginación nunca son el producto de operaciones puramente cognitivas, verificables empíricamente a través de datos duros. Están más bien animadas por fantasías, deseos, y siempre implican valoraciones comparativas entre lo propio y lo extraño. Tampoco están circunscritas a trabajos de ficción, como novelas, obras de teatro, o poemas. Circulan aún en ámbitos que podríamos llamar más formales, como en el de las ciencias que tienen que ver con el espacio y el territorio, a través de mapas, cartografías, y en la geografía misma como disciplina.

Un interesante ejemplo que ilustra mejor esta noción, que entrelaza y tensa lo material con lo simbólico, es el del uso de metáforas para describir el interior de una casa y cómo la misma se transforma a través de las experiencias que esas metá- foras puedan sugerir. Así, el espacio objetivo de una casa — sus esquinas, pasillos, habitaciones, sótano, medidas - es mucho menos importante que los atributos poéticos que le puedan ser asignados, y que generalmente son cualidades con un valor imaginario y figurativo que es posible nombrar y sentir. De esta forma, la casa puede estar encantada, puede ser acogedora, mágica, o descrita como una prisión. El espacio, entonces, adquiere un sentido emocional e incluso racional a través de un proceso poético en el que los elementos vacantes o anónimos son transformados en lo que en realidad le da el significado mismo (Said, 1978). ${ }^{3}$ Lo interesante acá es notar que el espacio objetivo es muchísimo menos importante que los efectos de lo que

3 En el ámbito del turismo, por ejemplo, una habitación de un hotel siempre es un espacio imaginado, generalmente como fuente de confort o placer. Lo mismo sucede con todo el hotel, o bien con el destino turístico en general, que adquiere connotaciones que van más allá de sus dimensiones tangibles, y que a la postre influyen enormemente en su funcionamiento real. 
Said denomina, utilizando, como se dijo anteriormente, el término acuñado por Gaston Bachelard (1975), la poética del espacio.

$\mathrm{Al}$ ser los atributos poéticos o metafóricos los que le dan sentido a un espacio o a un lugar, los mismos adquieren un matiz parecido al que Castoriadis (1975) le da a su idea de imaginario social, o Benedict Anderson (1983) a sus comunidades imaginadas, para referirse a su concepción de naciones modernas. Es decir, lo importante no es la falsedad o la veracidad de esos atributos, sino el efecto que tengan los mismos en el espacio y en cómo es imaginado, concebido, y, por ende, moldeado y construido.

El geógrafo británico Derek Gregory (1994), a partir de la idea de Said acerca de la distancia establecida y los atributos producidos por las geografías de la imaginación entre lo propio y lo extraño, y lo cercano y lo distante, trata de darle a esta noción un enfoque aún más abarcador. Propone que las geografías de la imaginación tienen un carácter performativo, en el sentido que producen los efectos que nombran. El espacio no es solamente el ámbito de lo material, sino que ejecuta acciones. Es decir, el espacio no es solamente algo imaginado aunque esta imaginación también le pueda conferir características que lo conviertan en parte inherente de su existencia-; también lo imaginado señala las prácticas que a la postre se producen en un determinado espacio. En el caso del estudio del espacio turístico, esta idea es fundamental para entender el modo en que el espacio y el paisaje no solamente son imaginados, sino que también tienen un carácter performativo en un imaginario turístico específico. Volviendo al caso de la controversial construcción del hotel RIU en Guanacaste, en la costa noroeste de Costa Rica, imaginar el lugar como un escenario apto para la práctica de actividades acuáticas típicas del sol y la playa, o bien imaginar el horizonte marino visto desde el balcón de una habitación como el paisaje ideal, comparte responsabilidad con la tala de árboles o con el haber dinamitado rocas y corales que dificultaban a los bañistas retozar en el mar.

Ahora bien, como último punto en el ámbito de los imaginarios, y que nos remite al plano inmediato del turismo, es importante aclarar, una vez más, que los imaginarios y el turismo están intrínsecamente relacionados. Uno sin el otro no sería posible. Es realmente difícil pensar en turismo sin pensar en imaginarios o fantasías. En el turismo contemporáneo, desde la idea romántica, de gran circulación, que se tiene de ciudades como París o Venecia, el mundo mágico y perfecto de Disney, lo fantasmagórico y lo extraordinario del castillo de Drácula en Rumanía, o bien lo paradisíaco de las playas del Caribe, la imaginación no se puede desligar del destino. No es posible, entonces, pensar en turismo solamente a partir de condiciones y fuerzas desencadenadas en la esfera de lo económico: existen también poderosos imaginarios sociales que lo sustentan.

En torno a este tema, es importante considerar el aporte de Noel Salazar, uno de los más conspicuos autores en torno a lo imaginario en el turismo a nivel global en la actualidad. Salazar (2012) elabora a partir de nociones como la de Paul Ricoeur (1994) acerca de lo imaginario como una función que produce significado, $y$, a la vez, el producto de esa función. Considera que los imaginarios son ensamblajes de representaciones que interactúan con las imaginaciones personales de la gente y se utilizan como forjadores de significado y de visión de mundo (Salazar, 2012). Sostiene también que muchos de estos imaginarios, en especial los turísticos, están estructurados por dicotomías, en ocasiones difícilmente reconocibles, y que representan al mundo en binomios ligados paradigmáticamente: naturaleza-cultura, aquí-allá, masculino-femenino-, adentro-afuera, y local-global. Otra idea de Salazar, y que coincide con las acotadas anteriormente a partir 
de teóricos como Said, Castoriadis o Taylor, es que los imaginarios no se expresan en términos teóricos, sino en imágenes y en discursos que todo el mundo entiende. Las imágenes existen por medio de representaciones o entendimientos implícitos, aun cuando adquieran una gran fuerza institucional. A la vez, son el medio a través del cual los individuos comprenden sus identidades y su lugar en el mundo.

Salazar afirma, siguiendo a L.L. Wynn (2007) que, en el caso del turismo, estos imaginarios se convierten en tangibles cuando se encarnan en instituciones, sitios arqueológicos, museos, monumentos, hoteles, y en los medios de comunicación - ya sean tradicionales o digitales-, y en otras producciones culturales. A través de estos medios, potenciales turistas son invitados a imaginarse a sí mismos en ambientes paradisíacos en los que tanto el paisaje como la población local están prestos a ser consumidos a través de la observación, las sensaciones corporales y la imaginación.

Según estos atributos, entonces, los imaginarios turísticos no emergen de las experiencias concretas y cotidianas de las personas, sino de las imágenes colectivas. Por lo tanto, no deben ser consideradas simplemente como representaciones comerciales de lugares y personas con un contenido simbólico o interpretativo. Más bien propagan estereotipos heredados históricamente, que forman parte de imaginarios sociales mayores.

Los discursos del pasado, entre los que se encuentran el orientalismo, el colonialismo y el imperialismo, al parecer son territorio fértil de sueños románticos y nostálgicos dentro del turismo. En el caso de los países periféricos, es decir, en un contexto como el caribeńo, los imaginarios son primordialmente acerca de fantasías que contienen una nostalgia ambivalente con el pasado, en las que se enfatiza sus factores aparentemente benévolos, y, a la vez, se oculta la dominación colonial brutal a la que, anteriormente, esos destinos fueron sometidos (Salazar, 2012).

Implícita en estas fantasías e imaginarios también está la idea, expuesta por Graham Dann (1976), que afirma que estos comparten, primordialmente, dos características: por un lado, salir de la monotonía y la supuesta falta de significado de la vida cotidiana a través de experiencias gratificantes como el escapismo y el deseo por lo exótico, y, por otro lado, la exaltación del ego a través de la acumulación de capital simbólico. Estos deseos, tanto de escapismo como de acumulación de capital simbólico, no necesariamente corresponden a aspiraciones internalizadas de carácter individual. Más bien son parte de imaginarios mayores, ampliamente compartidos, y que se articulan a través de prácticas sociales y medios de comunicación, en todas sus variantes.

Otro punto importante a tener en cuenta, en cuanto a los imaginarios turísticos, es que no es precisamente la diferencia y lo extraordinario lo que motiva y nutre al turismo, sino más bien lo opuesto: la extensión de la pertenencia y de lo propio. A pesar de que se proyecta la diferencia, en los imaginarios turísticos lo que se hace realmente es resaltar imaginarios propios acerca de otras geografías y pueblos, hecho que los convierte en un vehículo para destacar la otredad, al tiempo que se afirman los valores de la cultura propia. Las historias, imágenes y deseos que abarcan marcos referenciales de imaginarios esencialistas, míticos, y exóticos, entonces, a menudo funcionan como el motor escénico que pone a la maquinaria del turismo en movimiento.

Acá es clara, por un lado, la relación entre lo simbólico y lo funcional, según la idea de Castoriadis, a la hora de establecer la representación y la funcionalidad de un destino turístico ante los ojos de un visitante; lo prescriptivo de ciertas nociones 
imaginarias occidentales, que proyectan una visión de mundo estándar versus los otros imaginarios, y que es fácilmente detectable en los imaginarios turísticos de países periféricos; y, por supuesto, la pertinencia de la noción de las geografías de la imaginación de Said, derivadas de la poética del espacio de Bachelard, especialmente en un campo como el turismo, plagado de narraciones y representaciones llenas de metáforas, escritas y visuales, que transforman los espacios objetivos en espacios poblados de símbolos y significaciones.

\section{Imaginación y devenir turístico en Costa Rica: de la selva al resort}

La primera gran asociación de Costa Rica con los imaginarios turísticos es la de ser un paraíso tropical, inexplorado, verde, y que invita al turista a convertirse en un explorador conquistador contemporáneo, que revive la fantasía de escapar de la cotidianidad moderna para imbuirse en un mundo primigenio, rodeado de junglas exóticas, pobladas por animales cuasi fantásticos, presto a ser consumidos por la mirada y las experiencias del turista. Esta idea de impulsar este tipo de imaginario tiene un comienzo, al menos su implementación formal, en 1984, cuando el Instituto Costarricense de Turismo optó por posicionar al país como un destino de naturaleza, con una campańa publicitaria cuyo lema era "Costa Rica: it's only natural", y así diferenciarse de otros destinos vecinos, principalmente en el Caribe, que más bien enfatizaban el sol y la playa (Instituto Costarricense de Turismo, 2017).

Entre 1985 y 2014, bajo el lema "No Artificial Ingredients", todas las campañas enfatizaron los atractivos naturales del país, como sus parques nacionales, sus volcanes, y sus playas, vistas entonces como extensiones de esa naturaleza exuberante que se promocionaba, y no como el lugar del resort todo incluido. El componente humano y cultural siempre pasó a un segundo plano, y, básicamente, lo que se resca- taba era la imagen de la tradición democrática y la estabilidad política del país, especialmente en una época en la que sus vecinos centroamericanos se enfrascaban en guerras fratricidas. Esta diferenciación a nivel social y cultural con respecto a los países aledaños, altamente presente en la identidad nacional costarricense, también implicaba la idea de dotar al país, como destino turístico, de un halo de confort y seguridad que no tenían otras naciones del área.

Sin embargo, de modo paralelo, en provincias costeras como Guanacaste y Puntarenas se comienzan a incentivar proyectos de desarrollo inmobiliario y de enclaves turísticos parecidos a los de países vecinos que habían optado por el turismo de sol y playa, como República Dominicana, Cuba o el Caribe mexicano. La génesis de estos proyectos aparece en 1979, cuando se aprueba la Ley 6370, (Asamblea Legislativa, 1979) en el congreso costarricense. El mismo destinaba una porción específica de Bahía Culebra, en Guanacaste, para el desarrollo del turismo de sol y playa de enclave, y rebautiza la misma bahía con el más atractivo nombre de Golfo de Papagayo, homónimo del proyecto, posteriormente denominado Polo Turístico de Papagayo. En esta Ley, el Estado se comprometía a facilitar la infraestructura, que iba desde caminos de acceso, electricidad y agua, hasta un aeropuerto internacional. También facultaba al Instituto Costarricense de Turismo a expropiar los terrenos que fueran necesarios para la instalación de los hoteles, con el fin de facilitar la inversión extranjera directa de las grandes cadenas hoteleras globales. ${ }^{4}$

\footnotetext{
4 Antes de la crisis mundial provocada por el COVID-19, que golpeó especialmente al turismo, Costa Rica recibió, en el año 2019, más de 3.000.000 de visitantes, lo que se tradujo en ingreso de divisas en US\$ 3.657 millones. Desde inicios de la década de los noventa del siglo pasado, hubo un incremento significativo de turistas, lo que convirtió a esta actividad en una de las principales fuentes de ingresos del país, muy por encima de la exportación de productos tradicionales como el café o el banano. (Blanco, 2019).
} 
En la última década del siglo xx y en la primera del XXI, hasta la crisis mundial del 2008, este proyecto se concretaría. Otras zonas de esa provincia y de Puntarenas, como Tamarindo, El Coco o Jacó, también verían un explosivo desarrollo inmobiliario de infraestructura hotelera y de segundas residencias nunca antes visto en el país, y que competía, contrastaba, y a menudo superaba la idea original de promocionar un país verde y exuberante de naturaleza. El contraste se daba principalmente a partir del impacto ambiental de estos proyectos, que más tarde estarían, como se mencionó al principio de este trabajo, en la mira de muchos investigadores, tanto costarricenses como extranjeros, así como en la de organizaciones ambientalistas. Superada la crisis financiera mundial, este tipo de desarrollo inmobiliario parece haberse recuperado, y de nuevo existe un boom de la construcción en estos destinos y otros que también se han unido. A la fecha se anuncia una gran nueva ola de inversión inmobiliaria en Guanacaste (Gómez, 2019).
La combinación de estas estrategias de desarrollo turístico: por un lado, la de presentar al país como destino de turismo de naturaleza; por el otro, como un destino de sol y playa que podía competir con sus vecinos caribeños, estableció un contrapunteo entre la selva y los volcanes, y las segundas residencias y los resorts todo incluido. Esto devino en corrientes de desarrollo turístico muy particulares y variadas para un país tan pequeño. Estas tendencias, a su vez, empezaron a sustentar y a ser sustentadas en un proceso simbiótico, por imaginarios turísticos que no solamente eran el simple acompańamiento promocional que podría suponer una campaña mediática acerca de un país — un modo muy simplista de ver el asunto- , sino que se imbricarían con las prácticas turísticas y con los desarrollos inmobiliarios, con características de corte rizomático, y con consecuencias mucho más allá de lo sospechado.

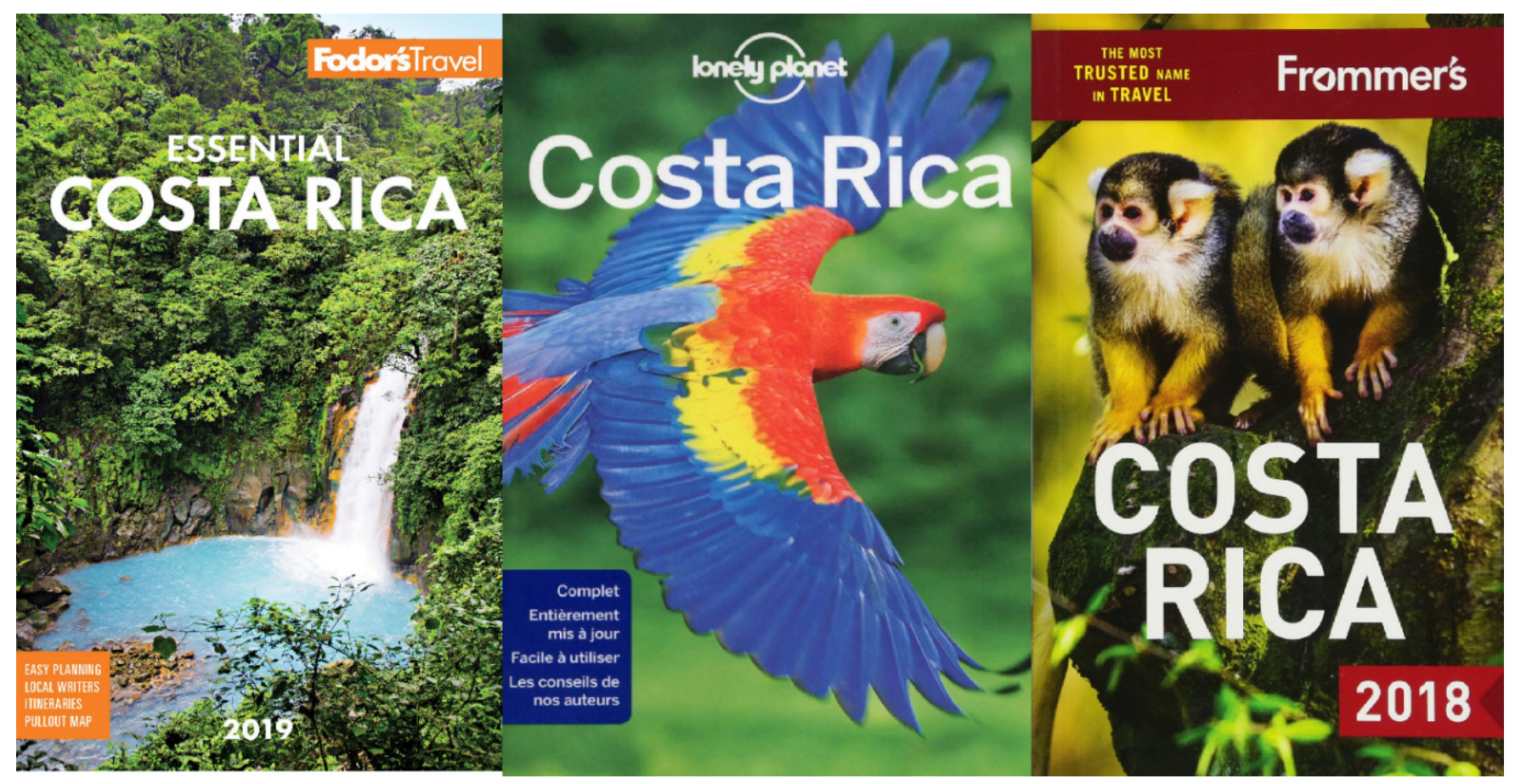

Figura 2. Portadas de ediciones recientes sobre Costa Rica de las populares guías de viaje Fodor's, Lonely Planet y Frommer's

Fuente: amazon.com 
A la par de estas políticas de desarrollo turístico se comienzan a generar y a circular imaginarios que no necesariamente vienen de organismos oficiales. También aparecen y se propagan en las guías de viajes, como Fodor's, Frommer's o Lonely Planet; a través de escritores de viajes profesionales, muchas veces pagados por los mismos empresarios hoteleros o de desarrollos inmobiliarios; en publicidad, por parte de las mismas corporaciones hoteleras, aerolíneas y agencias de viajes; y entre los mismos turistas, como puede corroborarse fácilmente a través de la observación de lo que publican en sus redes sociales acerca de sus visitas al país. Obviamente, no podemos olvidar las múltiples campañas publicitarias lanzadas a nivel internacional por el Instituto Costarricense de Turismo, en las que la selva, las playas, los volcanes, y los animales salvajes - dimensionados como principales habitantes de esas tierras-, invitaban al posible visitante a escaparse de su industrializada cotidianidad y a sumergirse en el mundo natural del país.

Entonces, Costa Rica empieza a ser representada como un paraíso tropical ideal para vacacionar, donde es posible, según una guía como Fodor's (s.f., p.1) admirar volcanes mientras se está sumergido en aguas termales, caminar por el bosque lluvioso y luego aprender a surfear en un hotel de lujo, recorrer kilómetros de playas prístinas en las costas del Pacífico y el Caribe, visitar fabulosos parques nacionales con abundantes oportunidades para ver vida salvaje, hospedarse en hoteles ecológicos de fama mundial, entre otras actividades. O bien, según Lonely Planet (2020, p. 1), el país es un escenario repleto de playas desiertas rodeadas de junglas, lagunas nubosas que forman cráteres en volcanes, rápidos para recorrer en balsas y kayaks, doseles donde es posible hacer zip-lining, o playas bañadas por el sol que brinda a los bañistas atardeceres multicolores.

En cuanto a la atracción de inversionistas, las mismas agencias de bienes raíces, totalmente independientes del Estado, comienzan a promover al país como una tierra de oportunidades para "iniciar una nueva vida", según sus anuncios en internet o en las vallas publicitarias cercanas a los proyectos de segundas residencias que promocionan, la mayoría cercados y aislados estratégicamente del resto de las poblaciones locales. El clima tropical durante todo el año se presenta como un aliado que permite al inversionista escapar de la crudeza del invierno en el hemisferio norte y refugiarse en las cálidas costas del Pacífico costarricense, en un país que está dispuesto a acoger al inversionista "con los brazos abiertos" y con casi ninguna traba migratoria (Krain Luxury Real Estate, 2019).

En cuanto a aspectos políticos, sociales y económicos, se enfatiza y garantiza al inversionista la estabilidad política del país, la inexistencia, supuestamente, de agitación social, bajos índices de criminalidad, comparados con los de países vecinos, y la existencia de infraestructura clave, como aeropuertos, cerca de los polos turísticos que se promociona (Krain Luxury Real Estate, 2019). También se destaca el continuo crecimiento del mercado inmobiliario y el supuesto buen nivel educativo de la población local.

A nivel de políticas estatales de promoción de inversiones en áreas como el turismo, se presenta al país como un lugar de oportunidades, como la cuna del talento humano, y como líder mundial en energía renovable (Esencial Costa Rica, 2019). Estos atributos se combinan con el énfasis estatal en la preservación de la biodiversidad del país, la considerable cobertura boscosa y lo bien conectada que está la nación, a través de rutas aéreas, con el resto del mundo.

Se da, entonces, una interacción entre estos relatos e imágenes, que motivan fantasías entre posibles visitantes e inversionistas, y la percepción acerca del propio país, tanto de turistas como de habitantes locales, ya sean estos relacionados o no con el turismo. Los imaginarios turísticos pasan a fundirse y a interactuar con los imaginarios nacio- 
nales históricos, y, aparte de valores tradicionales que le han dado a los costarricenses una identidad diferenciadora de países vecinos, como los supuestos principios democráticos, el pacifismo o la laboriosidad, se suman nuevos atributos como la conservación de la naturaleza, la cultura de sostenibilidad ambiental, o la supuesta felicidad de sus habitantes, en plena concordancia con la imagen del local ameno y sonriente que vive en un paraíso tropical y lo conserva para que los turistas puedan gozar de él.

Toda esta combinación, lo que se desea proyectar, los imaginarios que se producen y el capital simbólico de los turistas y los inversionistas, -lo que Jafar Jafari (1996) llama the carry on culture, es decir, el bagaje social que inevitablemente el turista va a llevar consigo mismo a todos los destinos que visita- surte, entonces, efectos notables en el carácter performativo de los atractivos turísticos del país, tanto los de naturaleza, como los de sol y playa, y las comunidades circundantes. La promesa del nuevo comienzo en el paraíso de las costas de las provincias de Guanacaste o Puntarenas, por ejemplo, una idea promocionada entre potenciales compradores de casas de veraneo, se refleja en los modos en que los desarrollos inmobiliarios de segundas residencias son construidos a lo largo de sus costas.

Amparada en esta oferta surge una gran cantidad de condominios, desarrollados en forma masiva y con tremendo impacto ambiental, especialmente en cuanto al tema de la disponibilidad de agua. Estos anuncian la promesa de la comunidad cerrada, enclavada en medio edén tropical, que otorgará al comprador prestigio y un halo de exclusividad y distinción, materializado en una propiedad aislada de las realidades locales, en la que reina el confort y la seguridad, y en donde no importan las consecuencias que este tipo de desarrollo pueda generar en sus alrededores, como la especulación inmobiliaria, la gentrificación, o el ya mencionado impacto ambiental. Esto va a generar, como se dijo al principio de este trabajo, toda una serie de conflictos sociales y ambientales entre los desarrolladores y los pobladores locales, quienes, tal y como prometen los desarrollos inmobiliarios, quedan fuera de los enclaves de placer, tanto a nivel imaginario como en el de toma de decisiones acerca del uso del espacio público, el agua, o el valor de las tierras. Parte de las causas de esa falta de representatividad política es, precisamente, no formar parte del imaginario turístico.

Estos modos de imaginar el paisaje y, posteriormente, de construir el espacio, marcan tendencia incluso en cuanto a los estilos arquitectónicos implementados como resultado tangible de los imaginarios turísticos. En la costa pacífica del país, por ejemplo, especialmente en Guanacaste, las primeras inversiones con fines de segundas residencias comenzaron en los años setenta y ochenta del siglo pasado. En esa época se enfatizaba la creación de edificaciones en armonía con el ambiente, en concordancia con la idea de la Costa Rica "sin ingredientes artificiales", la que en ese entonces promovió la política de atracción turística estatal. Estas construcciones, algunas de las cuales aún existen en la costa caribeña, o en Monteverde, o La Fortuna, en la parte noroeste y norte del país, respectivamente, proyectaban la fantasía colonial del descubrimiento y del comienzo de una nueva vida en un paraíso tropical, recién colonizado y domesticado, en contacto directo con la naturaleza.

De este tipo de construcción, de tendencia hacia lo rústico, se pasó, a finales del siglo pasado, al estilo colonial o neocolonial (Loría, comunicación personal, 25 de junio de 2019) . En este, los muros

5 Donald Loría es arquitecto y gerente de proyectos radicado en Nosara. Ha estado a cargo del diseño y la construcción de importantes proyectos de segundas residencias y hoteles desde la década de los noventa hasta el presente, tanto en la zona de Nosara como en Santa Teresa, además de países como Nicaragua o México. Desde su profesión ha sido testigo de las tendencias inmobiliarias y arquitectónicas de la costa de Guanacaste durante los últimos 30 años. 
exteriores y los arcos en los portones indicaban el límite entre las segundas residencias y los hoteles, por un lado, y el resto del entorno, por el otro. Al mismo tiempo, los diseños interiores y los techos de tejas replicaban edificios de distintos contextos coloniales españoles, desde México hasta Sudamérica. El enclave de exclusividad comenzó a imitar, a nivel de diseño arquitectónico, contextos en los que, anteriormente, las construcciones habían servido de contingencia y límite entre lo conquistado y lo civilizado, por una parte, y lo prístino y lo salvaje, por la otra. Los grandes proyectos de segundas residencias en los que se prometía confort, aislamiento y exclusividad se plasman en un estilo neocolonial dominante que, ciertamente, establece límites e indicadores de exclusividad muy claros y, al mismo tiempo, evocan un pasado colonial idealizado y descontextualizado. Acá el imaginario del enclave de sol y playa cerrado sustituye al imaginario de naturaleza prístina anterior. La promesa de exclusividad y confort se expresa en el aislamiento que estos proyectos prometen de las realidades locales, especialmente en regiones como Guanacaste, con mayores índices de pobreza y desigualdad que la media del país, y cuyas características sociales ciertamente desentonarían con lo que se promete al inversionista.

En una última tendencia, que rige en la actualidad, este estilo neocolonial es sustituido por inversiones y construcciones que los mismos arquitectos locales asocian con el trasplante de un penthouse, que podría estar en cualquier edificio de apartamentos de lujo en Manhattan, al medio de la selva. Esto está sucediendo especialmente en ciertas zonas de Guanacaste, como Nosara, o en el Pacífico Central, como en Quepos. En este nuevo estilo, los límites entre el enclave de lujo y exclusividad y el mundo exterior son aún más pronunciados. Las casas con amplios ventanales parecen dar la impresión, especialmente desde su interior, de que es posible observar y dominar con la mirada el entorno natural casi como a través de una pantalla gigante. Es decir, desde el pent-house trasplantado es posible mirar directamente la selva y la playa, pero sin tener contacto con ellas.

Este aspecto de esta nueva tendencia es muy interesante en cuanto a que replica esa idea de una imaginación y una mirada abarcadoras, desde perspectivas de poder, como lugares altos, y que consumen grandes cantidades de terreno y generan una ilusión panóptica, al tiempo que permiten a quien mira no ser parte de las realidades del paisaje observado. La naturaleza se convierte en una mercancía visual que se puede tener desde el enclave. Se da, entonces, en este estilo, la concreción física de esa particular combinación, tan característica del imaginario turístico costarricense: el enclave cerrado, pero en el que, al mismo tiempo, se le hace un guiño a la naturaleza, eso sí, vista como un bien más, que le otorga valor al lugar, y, a la vez, le confiere capital simbólico al que pueda tener contacto sensorial con ella desde esa perspectiva. La obra final, entonces, queda subordinada a lo que dictan los imaginarios que la producen, y no solamente los vaivenes económicos o las tendencias arquitectónicas propias del contexto.

Por último, en cuanto al carácter performativo de las geografías de la imaginación, es decir, lo que la forma de imaginarse un lugar indica en cuanto a las actividades que se pueden practicar en ese lugar, las costas del país, o bien sus montañas, promueven ciertas dinámicas sociales, a menudo con consecuencias no previstas dentro de la organización y el planeamiento formal del destino turístico en sí, y que en parte devienen de la forma en que son imaginadas. En destinos litorales, especialmente en la costa pacífica del país, es muy común, especialmente entre pobladores locales, la práctica de ciertos hábitos que evocan lo prometido en el imaginario hedonista del sol y la playa. Esto sucede en parte con el fin de asegurarse una cuota de participación en la supuesta promesa de derrama económica y simbólica del turismo. De este modo, 
muchos habitantes locales asienten a aparecer y a comportarse en los términos en que el discurso dominante acerca de lo que es el destino turístico los imagina.

Entre muchos jóvenes pobres de comunidades costeras marcadas por el impacto de la inversión y llegada de turistas que buscan el sol, la playa y los excesos que esta combinación promete, existe la interiorización de ideales estéticos y de consumo favorecidos en este tipo de imaginarios. Su existencia exitosa en el sistema turístico local depende completamente de su performatividad, ya sea a través de la estética surf, la estética rastafari, o la estética del sol y playa, que pueda hacer creer a los que la interioricen que pueden tener una mayor participación en el sistema. La supuesta seducción de lo exótico intentado en estas representaciones, y la posibilidad de que ese exotismo los haga atractivos dentro del imaginario turístico local lleva a muchos habitantes locales a tratar de impostar esas actuaciones con tal de poder participar de esa derrama simbólica, dado que de otra forma no tendrían acceso, ya sea por su bajo nivel educativo o sus condiciones de pobreza.

En los estudios turísticos, el trabajo de Jacqueline Sánchez (2006) acerca del turismo sexual femenino, en el que la cuestión de los imaginarios y la dicotomía entre el turista occidental y el otro local se vuelven tan o más importantes que las cuestiones de género para explicar el fenómeno, es sumamente valioso para entender más a fondo este asunto de representarse a sí mismo según los términos de quien mira y consume. A esta performatividad le suele acompañar la práctica de hábitos decadentes como alto consumo de alcohol y drogas, actividades criminales relacionadas con drogas que surten estos mercados costeros, prostitución, desintegración familiar, y otros problemas que ciertamente han contribuido enormemente a transformar la vida cotidiana de estas poblaciones en la era del turismo. Dichosamente esta no es la regla en todos los destinos turís- ticos del país y comunidades como La Fortuna o Monteverde, en donde se practica turismo de naturaleza Los actos performativos derivados de la forma en que estos lugares son imaginados y representados tienden más hacia la conservación del ambiente y una inclusión mayor de los pobladores locales en el turismo, no solo como empleados, también como emprendedores.

Los imaginarios turísticos, y no solamente los aspectos económicos, o los derroteros estatales en cuanto a políticas turísticas, también deben ser sujetos de análisis para entender este tipo de performatividad. A menudo, en análisis de corte moralista -entendiendo la moral como la capacidad humana de imaginar y pensar en cómo deberían de ser las cosas, y no simplemente describir las cosas como son (Caton, 2012) — el factor de la imaginación no es tomado en cuenta en los estudios acerca de las consecuencias del desarrollo turístico en ciertos espacios, como los litorales costarricenses, por ejemplo. La performatividad en estos lugares, tanto de turistas como de habitantes locales, no puede ser explicada únicamente a partir de factores económicos. En primera instancia, ambas partes actuarán según se imaginan a sí mismas, según los discursos históricos y culturales que moldean sus formas de ver el mundo.

\section{A modo de conclusión: lo imperativo de atender lo multidimensional en la implementación y promoción de políticas públicas en turismo y en el análisis de su impacto}

Si algo queda claro a partir de estas reflexiones en cuanto a la relación entre turismo e imaginación, es que el turismo no puede ser analizado sin tomar en cuenta su carácter multidimensional y sistémico, que incluye la variable de los imaginarios sociales. Es bastante deficiente, entonces, abordar el turismo como campo de estudio, o bien con el fin de implementar políticas de atracción de inversión o turistas, solamente a partir de ciertos 
factores como los económicos o los geográficos. El carácter sistémico y rizomático del turismo obliga a prestar atención a elementos, en primera instancia insospechados, que se entrelazan e interactúan con aspectos más evidentes y tradicionalmente más tratados y estudiados.

El énfasis dominate, en contextos como los que trata este artículo, que se le da a aspectos economicistas, o bien a la gestión pública, generalmente dejan por fuera perspectivas como la cuestión de los imaginarios, que, en un contexto como el centroamericano o el caribeño, es fundamental, dentro del sistema turístico en sí, para entender a cabalidad el funcionamiento del turismo, así como para poder incidir en su desarrollo de modos más inclusivos y equitativos. Esta variable también permite ver lo contradictorio que puede ser un modelo de desarrollo turístico, aunque, inicialmente, y si se toman solo aspectos como la oferta y la demanda, o la generación de divisas o inversión extranjera directa, no lo parezca.

Es imprescindible superar las barreras epistemológicas que conduzcan a pocas salidas de los muchos laberintos que plantea el estudio del turismo y los impactos que provoca, muchos de ellos muy negativos para las poblaciones locales. En el caso de los imaginarios sociales, su estudio e incorporación plena como elemento clave del turismo conducirá a ampliar el arsenal teórico disponible, para así poder entender las consecuencias de la imaginación y sus interacciones con las formas en que los destinos turísticos operan, se desarrollan, o perecen. Renunciar al "verismo" ingenuo de las imágenes o los relatos acerca de un lugar es clave para lograr esta incorporación. También es fundamental dejar de ver estos relatos e imágenes como simple publicidad que acompaña la circulación de un destino, o bien lo imaginario como ocurrencia o ficción. Ya Jafar Jafari y Bren Ritchie (1981), desde los años ochenta del siglo anterior enfatizaban la necesidad de entender el carácter multidisciplinar de los estudios turísticos, y la necesidad de establecer interacciones entre distintas disciplinas con tal de entender mejor el fenómeno, planear de manera más amplia su implementación, y prever mejor sus consecuencias.

Un cambio en el funcionamiento de un destino turístico en particular, en caso de que se considere necesario porque acarree consecuencias negativas para actores locales, o bien el medio ambiente, no depende solamente de factores económicos, de vaivenes políticos regionales o globales, o de elementos geográficos o sociológicos. Depende de una combinación de todos estos factores, y de otros, entre ellos los imaginarios turísticos, las estrategias discursivas, las narrativas y las distintas formas de representación. Un abordaje cualitativo, analítico y crítico de la forma en que los imaginarios interactúan con el desempeño de un destino es esencial a la hora de planear políticas públicas, y las mismas deben considerar distintas variables epistemológicas y filosóficas.

El turismo no se puede pensar sin cultura, tampoco como algo desligado de la percepción y la imaginación. Por algo, cuando se decide comprar, por primera vez, un pasaje de avión a otro lugar, sin haber estado nunca ahí, es la interacción entre imágenes, discursos, y nuestro propio bagaje cultural lo que en primera instancia nos forma una idea de ese lugar, e incluso influye enormemente en la compra de ese tiquete. Una vez en ese lugar, muchas de las experiencias que vivamos, los sitios que visitemos, los que evitemos, lo que comamos, o lo que experimentemos estarán en parte determinados por los resultados de esa imaginación y esa percepción previas. Un planeamiento turístico más abarcador debe irremediablemente incluir estos aspectos. Lo mismo debe suceder con la búsqueda de soluciones ante las consecuencias imprevistas de ciertos tipos de desarrollo turístico. 
Lo que consideramos real o concreto en una sociedad, o, en el caso particular del turismo, en un destino turístico, no puede disociarse nunca de lo simbólico. No se trata de diseñar una campaña publicitaria independiente del entramado simbólico asociado a cierto lugar, o bien de pensar que una campaña publicitaria va a determinar las formas en que un lugar es percibido. Eso es imposible, y solo pensarlo es ingenuo. Todos los enunciados que se desprendan de un imaginario turístico específico, en este caso, de un país como Costa Rica, están inextricablemente relacionados con su historia, con su cultura, y, muy importante, con el modo en que sus habitantes se auto perciben, con su identidad, y con las formas en que los turistas como consumidores se imaginan ese destino. Además, esos imaginarios turísticos estarán siempre ligados a imaginarios sociales mayores. En el caso del turismo en países de la cuenca del Caribe, a discursos coloniales de viaje al pasado, al encuentro con la naturaleza primigenia, reminiscente de exploraciones del pasado, las fantasías hedonistas asociadas al sol y a la playa, el habitante nativo como atento a servir a un turista-consumidor de ciertas experiencias, entre ellas ser servido y atendido, por ejemplo.

Existe entonces una continua interacción y entrelazamiento entre los imaginarios sociales, los turísticos, y el funcionamiento real del destino. Esa relación siempre sucederá, en cualquier destino, en cualquier país. Es decir, la aplicabilidad de la variante imaginaria es viable en todo lugar, y, más que viable, es necesaria si queremos tener una mejor comprensión de los modos en que un destino turístico funciona $y$, al mismo tiempo, poder incidir en su funcionamiento a través del incentivo de ciertos discursos en los que tanto los habitantes locales como sus recursos puedan tener una participación más equitativa en el sistema turístico.

\section{Referencias}

Asamblea Legislativa. (1979). Declara de utilidad pública los bienes inmuebles para realizar y ejecutar el proyecto turistico en Bahía Culebra o Papagayo $N^{\circ}$ 6370. Recuperado de http://www.pgrweb.go.cr/scij/Busqueda/ Normativa/Normas/nrm_texto_completo. aspx?param $2=$ NRTC $\&$ nValor $1=1 \& n V a-$ lor2=1352\&strTipM=TC

Aledo, A. (2008). De la tierra al suelo: La transformación del paisaje y el nuevo turismo residencial. Arbor: Ciencia, pensamiento y cultura, 184(29), 99-113.

Amin, S. (1974). Accumulation on a World Scale: A Critique of the Theory of Underdevelopment. Nueva York: Monthly Review Press.

Anderson, B. (1983). Imagined Communities: Reflections on the Origin and Spread of Nationalism. Londres: Verso.

Arias, R. y Coronado, J. (2010). Conflictividad socio-ambiental en la Península de Osa. El caso de las Marinas Turísticas en el Golfo Dulce, Costa Rica. En E. Cañada (ed.). Turismo y conflictos socioambientales en Centroamérica. Managua: Fundación Luciérnaga.

Bachelard, G. (1975). La poética del espacio. México: Fondo de Cultura Económica.

Baldacchino, G. (2005). The Contribution of "Social Capital" to Economic Growth: Lessons from Island Jurisdictions. The Round Table, 94(1), 31-36.

Blanco, E. (2019). ¿Ha valido la pena? Desarrollo turistico en Guanacaste, Costa Rica: resultados a nivel ambiental y social (1990-2016). San José: Universidad de Costa Rica, Vicerrectoría de Investigación: Centro de Investigaciones Históricas de América Central.

Britton, S. (1982). The Political Economy of Tourism in the Third World. Annals of Tourism Research, 9(3), 331-358. 
Campling, L. (2006). A Critical Political Economy of the Small Island Developing States Concept: South-South Cooperation of Island Citizens? Journal of Developing Societies, 22(3), 235-285.

Cañada, E. (2010). Turismo y conflictos socioambientales en Centroamérica. En E. Cañada (ed.). Managua: Fundación Luciérnaga.

Cañada, E. (2011). Conflictividad turística en Centroamérica. En M. Blázquez y E. Cañada (eds.). Nueva colonización turística: del Mediterráneo a Mesoamérica y el Caribe. Lógicas espaciales del capital turístico. Managua: EDISA.

Castoriadis, C. (1975). La institución imaginaria de la sociedad. Barcelona: Tusquets Editores.

Castoriadis, C. (1998). El avance de la insignifcancia. Madrid: Cátedra.

Caton, K. (2012). Taking the Moral Turn in Tourism Studies. Annals of Tourism Research, 39(4), 1906-1928.

Chaperon, S. y Bramwell, B. (2013). Dependency and Agency in Peripheral Tourism Development. Annals of Tourism Research, 40, 132-154.

Cordero, A. (2006). Nuevos ejes de acumulación y naturaleza: El caso del turismo. Buenos Aires: CLACSO.

Costa Rica Information. (2019). Why Invest in Costa Rica. Recuperado de http://costarica-information.com/about-costa-rica/ economy/economic-sectors-industries/ real-estate/purchase-investment/why-investin-costa-rica

Dann, G. (1976). The Holiday Was Simply Fantastic. Revue de Tourisme, 3, 19-23.

Fodor's Costa Rica Travel Guide. (s.f.). Recuperado de htpp://fodors.com/world/mexicoand-central-america/costa-rica

Frank, A. (1978). Dependent Accumulation and Underdevelopment. Londres: Macmillan.

Gómez, D. (2019). Claudia Dobles anuncia inversión de \$418 millones y generación de 7 mil empleos en región Chorotega. Recuperado de https:// ncrnoticias.com/nacionales/claudia-doblesanuncia-inversion-de-418-millones-y-generacion-de-7-mil-empleos-en-region-chorotega/

Gregory, D. (1994). Geographical Imagination. Oxford: Blachwell.

Esencial Costa Rica (2019). Marca país. Recuperado de https://www.esencialcostarica.com/

Frank, A. (1978). Dependent Accumulation and Underdevelopment. Londres: Macmillan.

Instituto Costarricense de Turismo (2017). Plan nacional de desarrollo turístico de Costa Rica 2017-2021. Recuperado de https://www. ict.go.cr/en/documents/plan-nacional-y-planes-generales/plan-nacional-de-desarro1lo/1071-plan-nacional-de-desarrollo-turistico-2017-2021/file.html

Jafari, J. y Ritchie, B. (1981). Toward a Framework for Tourism Education. Annals of Tourism Research, 8(1), 13-34.

Jafari, J. (1996). Tourism and Culture: An Inquiry into Paradoxes. En F. Childe (ed.). Culture, Tourism, Development: Crucial Issues for the $21^{\text {st }}$ Century. Paris: UNESCO.

Krain Luxury Real Estate Costa Rica. (2019). Why Investment in Real Estate in Costa Rica Makes Sense. Recuperado de https:// kraincostarica.com/en/about-krain-real-estate-costa-rica/krain-resource-center/ investing-in-costa-rica?gclid=EAIaIQobChMIyP3W1Iya5AIViQOGCh2v0APSEAAYASAAEgL8AvD_BwE

Hernández, A. y Picón, J. (2012). En la frontera del conflicto socioambiental: El modo de vida rural y el desarrollo del turismo de sol y playa en Guanacaste, Costa Rica. Ambientales, 42(2), 31-44.

Lobo, D. (2016). Sueños que son pesadillas: propagación del turismo de élite y menoscabo ecológico en el Pacífico Central de Costa Rica. Cuadernos intercambio sobre Centroamérica y el Caribe, 13(2), 164-180.

Lonely Planet Costa Rica (2020). Recuperado de https://www.lonelyplanet.com/costa-rica 
Molina, S. y Rodríguez, S. (1991). Planificación integral del turismo: Un enfoque para Latinoamérica. México: Trillas.

Morera, C. y Sandoval, L. (2008). En J. Picón y L. Morales (eds.). El modelo turístico de Guanacaste, Costa Rica: convivencia y conflicto. Desarrollo sustentable del turismo en Mesoamérica. Nicoya: CEMEDE.

Muñoz, F. (2007). Autopsia del turismo. Madrid: Eumend.

Navarro, S. (2013). Turismo e inmigración en Playa Matapalo, Sardinal, Costa Rica: resistencias comunitarias y laborales. Anuario de Estudios Centroamericanos, 39, 263-287.

Navas, G. y Cuvi, N. (2015). Análisis de un conflicto socioambiental por agua y turismo en Sardinal, Costa Rica. Revista de Ciencias Sociales, 150, 109-124.

Nash, D. (1989). Tourism as a Form of Imperialism. En V. Smith (ed.). Hosts and Guests: The Anthropology of Tourism. Philadelphia: University of Pennsylvania Press.
Ricoeur, P. (1994). Imagination in Discourse and in Action. En G. Robinson y J.F. Rundell (eds.). Rethinking Imagination: Culture and Creativity. London: Routledge.

Said, E. (1978). Orientalism. Nueva York: Vintage. Salazar, N. (2012). Tourism Imaginaries: A Conceptual Approach. Annals of Tourism Research, 39(2). 863-882.

Sánchez, J. (2006). Female Sex Tourism: A Contradiction of Terms? Feminist Review, 83, 42-59.

Taylor, C. (2006). Imaginarios sociales modernos. Barcelona: Paidós.

Van Eghen, S. (2011). Water conflicts in Costa Rica? Sardinal: A Case Study in the Emergence of a Water Conflict in the Context of High Speed Growth in (Residential) Tourism. Universiteit Utrecht: Utercht.

Wynn, L. (2007). Pyramids and Nightclubs: A Travel Ethnography of Arab and Western Imaginations of Egypt. Austin: University of Texas Press.

\section{Datos de filiación}

Esteban Barboza Núńez. Doctor en Estudios de la Sociedad y la Cultura, Universidad de Costa Rica. Sus líneas de investigación se centran en los estudios culturales y turísticos. 